\title{
Gender differences in physical activity motivators and context preferences: a population-based study in people in their sixties
}

Jannique G. Z. van Uffelen ${ }^{1,2,3^{*}}$, Asaduzzaman Khan ${ }^{4}$ and Nicola W. Burton ${ }^{2}$

\begin{abstract}
Background: Although regular participation in physical activity (PA) has health benefits across the life span, the proportion of people doing sufficient activity for these benefits decreases with age. The aim of this study was to identify motivating factors and context preferences for PA in people in their sixties, and to examine gender differences in these factors.
\end{abstract}

Methods: Data were used from people aged 60-67 years who responded to a mail survey in Brisbane, Australia, in 2009. Respondents indicated their agreement/disagreement with seven PA motivators and 14 PA context preferences. Data were analyzed using multi-level multinomial logistic regression, adjusted for sociodemographic and health variables, and PA level.

Results: Of the 1845 respondents, 59\% was female. Based on self-reported PA, one in three respondents (35\%) did not meet the PA guidelines of at least 150 min of moderate intensity PA per week. The three leading motivating factors for both women and men were to prevent health problems, to feel good and to lose weight. Women were more likely than men to be motivated by improving appearance (OR $2.93,95 \% \mathrm{Cl} 2.07-4.15)$, spending time with others $(1.76,1.31-2.37)$, meeting friends $(1.76,1.31-2.36)$ or losing weight $(1.74,1.12-2.71)$. The three leading context preferences for both women and men were for activities close to home, at low cost and that could be done alone. Women were more likely than men to prefer activities that are with people of the same sex (OR 4.67, $95 \% \mathrm{Cl} 3.14-6.94)$, supervised $(2.79,1.94-4.02)$, with people the same age $(2.00,1.43-2.78)$ and at a fixed time $(1.42,1.06-1.91)$. Women were less likely than men to prefer activities that are competitive (OR $0.32,95 \% \mathrm{Cl} 0.22-0$. $46)$, are vigorous $(0.33,0.24-0.47)$, require skill and practice $(0.40,0.29-0.55)$ and done outdoors $(0.51,0.30-0.86)$.

Conclusion: Although there was overlap in motivating factors and context preferences for PA in women and men aged 60-67 years, there were also marked gender differences. These results suggest that PA options for people in their sixties should be tailored to meet gender specific interests in order to promote PA participation in this rapidly growing population group.

Keywords: Physical activity, Exercise, Health, Aging, Population-based study

\footnotetext{
* Correspondence: Jannique.vanuffelen@vu.edu.au

1 Victoria University, Institute of Sport, Exercise and Active Living (ISEAL)

(office PB140), PO Box 14428, Melbourne, VIC 8001, Australia

${ }^{2}$ The University of Queensland, School of Human Movement and Nutrition

Sciences, QLD, Brisbane 4072, Australia

Full list of author information is available at the end of the article
} 


\section{Background}

As a result of population ageing, the proportion of older people is increasing rapidly. Worldwide, the proportion of people aged $65+$ years is predicted to increase from $8 \%$ in 2010 to $16 \%$ by 2050 [1]; this increase will be even more pronounced in developed countries. For example, the proportion of older people in Australia was $14 \%$ in 2012 and is predicted to increase to $20 \%$ by 2040 [2].

As the population ages, the number of adults with chronic health conditions and physical limitations will increase, leading to an increased burden on health care systems $[1,3]$. This is particularly the case in mid-old and older-old people, as the proportion of older adults without health conditions reduces from over 30\% in people in their early sixties, to just below $20 \%$ in people in their late sixties to mid-seventies and lower than $10 \%$ in people aged 75+ years [4]. Regular participation in physical activity (PA) is an important aspect of prevention and management of chronic conditions that are prevalent with increasing age, such as diabetes and cardiovascular disease [5]. Furthermore, PA has a beneficial influence on age related physical conditions such as falls and decline in functional status $[6,7]$, as well as on cognitive function and quality of life [7-9].

Lack of regular PA is associated with an increased risk of premature mortality. It is the fourth ranked mortality risk globally [10], estimated to cause $6-10 \%$ of deaths related to coronary heart disease, diabetes, and breast and colon cancer and $9 \%$ of premature mortality [3]. Furthermore, it contributes to increased health care costs as time spent in PA is a significant inverse predictor of subsequent numbers of prescriptions, medications, physician contacts and unplanned hospital admissions in older adults [11, 12]. Regular PA therefore is a key health behavior from a public health perspective, as it has a significant impact on health and on physical inactivity related health care costs [13]. As the numbers of older people will increase substantially over the coming decades, and age related conditions are a major contributor to the overall burden of disease [14], efforts to promote PA in this population group are critical.

In order to achieve health benefits, PA guidelines such as those from the World Health Organization [10], the American College of Sports Medicine [15] and the Australian Government [16], typically suggest that older adults do a minimum of 150 min of moderate intensity activity per week. Despite the health benefits of regular $\mathrm{PA}$, the proportion of the population meeting these PA guidelines decreases with age and ranges from 30 to $60 \%$ in people aged 60+ years worldwide [17]. In Australia, only $48 \%$ of Australian adults aged $65-74$ years do meet the PA guidelines and this proportion is less than $25 \%$ in adults aged $75+$ years [18].
In order to encourage older adults to be sufficiently physically active, it is important to understand what motivates them to be active and how they prefer to do physical activity. Much of the evidence on successful PA programs for older people is gathered from participants in those programs and there is a need to examine PA motivators and context preferences in more representative samples of older adults [19]. Evidence from larger samples suggests that older adults have a preference for activities that are not in formal group settings. This has for example been reported in a review paper including studies in people aged 50+ years [19], in a study examining PA preferences in people aged 50-64 years and people aged $65+$ years [20] and in a study including people aged 60-78 years [21]. Furthermore, another study in adults aged $60+$ years reported a preference for unstructured activities [22]. Other studies have indicated preferences for PA advice from a health professional or some instruction to support PA in people aged $50+$ years [20] and in those aged 60-78 years [21]. With regards to exercise in groups, adults in their sixties and seventies have a preference against exercise groups with younger people and a preference for exercise in groups with people in the same age group [23].

Although other studies have demonstrated gender differences in, for example, perceived environmental and psychosocial determinants of PA in adults aged 16-65+ years $[24,25]$, few have explored gender differences in motivating factors and context preferences for PA in older adults specifically. However, there are gender differences in PA participation in older adults, with women aged 50+ years [19], those aged 60+ years [26] and those aged 65+ years [27] less likely to do sufficient PA for health benefits than men. There are also gender differences in the typical ageing process, with women more likely to live longer with more health conditions [1]. This may influence the motivating factors and context preferences for PA.

The aim of this study was to identify motivating factors and context preferences for physical activity in older people and to examine if there were gender differences. As older adults are not a homogenous group, we focused on 'young older' adults in their sixties.

\section{Methods}

\section{Sampling and data collection}

Data were used from a population-based sample of 'younger old' adults in the HABITAT study, which assessed physical activity and associated factors among people living in Brisbane, Australia. The HABITAT baseline survey was conducted in 2007, when participants were $40-65$ years. The questions about motivating factors and context preferences were included in the 2009 HABITAT survey, when respondents were 42-67 years. 
For this study, we included people with a minimum age of 60 years, as people aged $60+$ years are referred to as older people by the United Nations [3]. After including all people aged 60 years who participated in the study, we obtained a sample of young older adults aged 60-67 years.

For the HABITAT baseline survey in 2007, a multistage probability sampling design was used to select a stratified random sample of 200 Census Collector's Districts (CCD) in Brisbane. From within each CCD, a random sample of 85 people aged 40-65 years was selected, using data from the Australian Electoral Commission. Data were collected using a mail survey. Further details on sampling and data collection have been described elsewhere [28]. The HABITAT study was approved by the Queensland University of Technology Human Research Ethics Committee. As this was a mail survey, there was no direct contact between researchers and participants. Survey return was therefore taken as informed consent. This form of consent was approved by the ethics committee. Of the 10,844 surveys sent in 2009, 7837 ( $74 \%$ of eligible cases) respondents returned the completed surveys with data. Of these respondents, 1937 were aged sixty year or over and did not have physical limitations to do PA (i.e. responded 'most of the time', 'all of the time' or had missing data for the question 'In the last year, has your health restricted you from doing PA?'). Data of 1845 people aged 60-67 years who provided data on their gender were included in the analysis for this study. The variable gender was missing for 92 participants, which is about $3.7 \%$ of the analytical sample.

\section{Measures}

Respondents rated their agreement/disagreement with seven motivating factors and 14 physical activity context preferences on a five point Likert scale (strongly disagree, disagree, unsure [motivating factors]/ no preference [context preferences], agree, strongly agree). The motivating factors related to health and wellbeing (e.g. 'to make me feel good', 'to reduce stress'), appearance (e.g. 'to lose weight'), and social aspects of PA (e.g. 'to meet new friends'). Questions about the PA context preferences have been used in previously published research and assessed format (7 items), location (2 items) and social setting (5 items) [29-31]. The original selection of these study variables in the HABITAT study was guided by social cognitive theory which purports that behavior is influenced by personal, environmental, and behavioral factors [32]. When applied to understanding physical activity behaviour [33], personal factors include demographic and biological variables (e.g., gender, age, weight, health); environmental factors include social contextual variables (e.g., supervision, competition, meeting people) and physical contextual variables (e.g., location, cost); and behavioral factors reflect attributes of physical activity (e.g., intensity, skill required, format). Details about questions are provided in Tables 2 and 3 and complete questions are included in Appendices A-B. Responses were skewed towards extreme values (i.e. strongly agree, strongly disagree) and were therefore collapsed into three categories (disagree, unsure [motivating factors]/ no preference [context preferences], agree).

Sociodemographic characteristics included gender, age, education, employment status, income and living arrangements. These were assessed using standard questions and categorized as detailed in Table 1.

Health-related variables included general health, body mass index (BMI), and psychological distress. Respondents were asked to rate their health as poor, fair, good, very good or excellent. BMI was based on self-reported height and weight and categorized according to the World Health Organization classification $\left(<25 \mathrm{~kg} / \mathrm{m}^{2}\right.$, $25-<30 \mathrm{~kg} / \mathrm{m}^{2}$ or $>30 \mathrm{~kg} / \mathrm{m}^{2}$ ) [34]. Psychological distress was assessed using the Kessler 6 scale, a reliable and validated scale to screen for mental health issues in population based surveys [35]. Respondents indicated the frequency of feeling sad, nervous, restless, hopeless, worthless, and that everything was an effort in the past week on a five point Likert scale ranging from none of the time [ 0 points] to all of the time [4 points]. The responses were summed and categorized into no distress (0-7 points) or some distress (8-24 points), using cut off points as identified previously [36].

Physical activity was assessed with the items from the Active Australia questionnaire [37], which has been used frequently in population based surveys and has acceptable reliability and validity in mid aged and older adults $[38,39]$. Respondents reported time spent walking briskly (3.33 Metabolic equivalents [METs]), in moderate (3.33 METs) and in vigorous leisure time PA in the previous week (6.66 METs). The sum of the products of time in each of these activities and the MET-value was calculated and categorized as no PA ( $<90$ MET.minutes), some PA (90-449 MET.minutes), or meeting PA guidelines ( $\geq 450$ MET.minutes). The category 'meeting guidelines' is comparable with $\mathrm{PA}$ guidelines of at least 150 min of moderate-intensity PA per week $[10,15,16]$.

\section{Statistical analysis}

Data were analyzed in Stata using multilevel multinomial logistic regression to reflect the multistage sample selection. A random intercept for $\mathrm{CCD}$ was included in the regression models to account for clustering within CCDs. The regression analysis with random effects was conducted using GLLAMM (generalized linear latent and mixed models) commands of STATA version 11.0 (StataCorp, College Station, TX, USA). The assumption of parallel regression, essential for ordinal logistic regression, 
Table 1 Sociodemographic characteristics, health-related characteristics and physical activity level of the respondents stratified by gender $(n=1845)$

\begin{tabular}{|c|c|c|c|c|c|}
\hline \multirow{2}{*}{ Sociodemographic characteristics } & \multicolumn{2}{|c|}{ Female $(n=1089)$} & \multicolumn{2}{|c|}{ Male $(n=756)$} & \multirow[t]{2}{*}{$P$-value } \\
\hline & & & & & \\
\hline \multirow[t]{2}{*}{ Age (Mean [SD]) } & 63.3 & 2.17 & 63.0 & 2.25 & $<.05$ \\
\hline & $\mathrm{n}$ & $(\%)^{a}$ & $\mathrm{n}$ & $(\%)^{a}$ & \\
\hline Highest Educational Qualification & & & & & .001 \\
\hline School only (up to 12 years) & 582 & $(54)$ & 272 & (36) & \\
\hline Certificate/Diploma & 247 & (23) & 265 & $(35)$ & \\
\hline University degree & 252 & $(23)$ & 219 & (29) & \\
\hline Employment Status & & & & & .001 \\
\hline Full time paid & 196 & $(20)$ & 308 & (44) & \\
\hline Part time/Casual paid & 212 & $(22)$ & 116 & $(16)$ & \\
\hline Not in paid work & 164 & $(17)$ & 36 & (5) & \\
\hline Retired & 403 & $(41)$ & 246 & $(35)$ & \\
\hline Gross Annual Household Income (AUD) & & & & & .001 \\
\hline$<41,600$ & 419 & $(49)$ & 223 & $(32)$ & \\
\hline $41,600-72,799$ & 237 & $(28)$ & 217 & (31) & \\
\hline $72,800-129,999$ & 135 & (16) & 163 & (24) & \\
\hline$\geq 130,000$ & 69 & (8) & 88 & (13) & \\
\hline Living arrangements & & & & & .01 \\
\hline Living alone & 287 & (30) & 176 & $(25)$ & \\
\hline Living with partner & 572 & $(59)$ & 397 & $(57)$ & \\
\hline Living with partner and children & 109 & $(11)$ & 121 & $(17)$ & \\
\hline Health related characteristics and physical activity & $\mathrm{n}$ & $(\%)^{a}$ & $\mathrm{~N}$ & $(\%)^{a}$ & \\
\hline Self-rated health & & & & & .53 \\
\hline Excellent/Very good & 490 & $(45)$ & 311 & $(42)$ & \\
\hline Good & 468 & (43) & 328 & $(45)$ & \\
\hline Fair/Poor & 131 & $(12)$ & 94 & (13) & \\
\hline Body Mass Index (kg/m²) & & & & & $<.001$ \\
\hline$<25$ & 453 & $(42)$ & 234 & (31) & \\
\hline$\geq 25-29.9$ & 399 & (37) & 363 & $(48)$ & \\
\hline$\geq 30$ & 217 & $(20)$ & 159 & $(21)$ & \\
\hline Psychological Distress & & & & & .87 \\
\hline No distress & 989 & (93) & 695 & (93) & \\
\hline Distress & 69 & (7) & 50 & (7) & \\
\hline Physical activity level & & & & & .21 \\
\hline None & 134 & (13) & 104 & (14) & \\
\hline Some & 231 & $(22)$ & 137 & (19) & \\
\hline Meeting guidelines ${ }^{b}$ & 672 & $(65)$ & 481 & $(67)$ & \\
\hline
\end{tabular}

AUD Australian dollar, $n$ number, $S D$ standard deviation; ${ }^{a}$ Column percentages may not add up to 100 because of rounding; ${ }^{b}$ Equivalent of at least 150 min/week of moderate intensity physical activity. Boldface indicates statistical significance $(p<.05)$

was assessed using the Brant test and the estimation procedure used was numerical integration (10 integration points) with adaptive quadrature in order to obtain more reliable estimates of parameters [40]. The multinomial logistic regression analysis used to examine the association between gender (i.e. independent variable) and preference for certain motivating factors and context preferences (i.e. dependent variable) was adjusted for possible confounding effects of sociodemographic characteristics (age, education, employment status, income, living arrangements), 
health-related variables (self-rated health, body mass index, psychological distress) and physical activity level. A significance level of 0.05 was used to indicate statistical significance and odds ratios and $95 \%$ confidence intervals are reported. The odds ratio's represent the likelihood of women agreeing with each of the motivating factors or context preferences (versus 'disagreement'), compared to men.

\section{Results}

\section{Participants}

Mean age of the 1845 respondents was 63.2 (SD 2.21) years and 59\% was female. Female respondents were slightly older than the male respondents $(p<.05$, see Table 1). There were some gender differences in sociodemographic characteristics, with more men than women having a higher education, fewer men not in paid work and more in a full time paid position, and men having higher income. Men were also less likely to live alone and more likely to live with their partner and children (all $p<.01$, see Table 1 ). Most people rated their health as good-excellent and a higher proportion of men had a BMI $>25 \mathrm{~kg} / \mathrm{m}^{2}(p<.05$, see Table 1$)$. There were no gender differences in physical activity levels; $65 \%$ of respondents met PA guidelines, $21 \%$ did some PA and $14 \%$ did no PA.

\section{Motivating factors}

The proportion of women and men indicating agreement or disagreement with each of the seven motivating factors is presented in Table 2. The leading three motivating factors for PA for both women and men, were 'to prevent health problems' (97\% of women and 96\% of men), 'to feel good' (95\% of women and $91 \%$ of men) and to 'lose/manage weight' ( $88 \%$ of women and $84 \%$ of men). The social factors 'spend time with others' (68\% of women and $52 \%$ of men) and 'meet new friends' (58\% of women and $38 \%$ of men) were endorsed by fewer respondents than the health and wellbeing-related factors. There were significant gender differences in the likelihood of endorsing several factors (Table 2). After adjusting for age, education, employment status, income, living arrangements, self-rated health, body mass index, psychological distress and physical activity level, women were more likely than men to agree with motivators of improving appearance (OR 2.93, 95\% CI 2.07-4.15), spending time with others (OR 1.76, 95\%CI 1.31-2.37), meeting friends (OR 1.76, 95\%CI 1.31-2.36) and losing weight (OR 1.74, 95\%CI 1.12-2.71).

\section{Physical activity context preferences}

The proportion of women and men indicating agreement or disagreement with the PA contexts relating to format, location and social setting is reported in Table 3.
Table 2 Agreement with motivating factors stratified by gender and gender differences in the likelihood to agree

\begin{tabular}{|c|c|c|c|}
\hline & Agree (\%) & Disagree $(\%)^{a}$ & $\begin{array}{l}\text { OR } 95 \% \mathrm{Cl} \text { for women } \\
\text { compared to men }\end{array}$ \\
\hline \multicolumn{4}{|c|}{ Prevent health problems } \\
\hline Women & 97 & 1 & $2.11(.76-5.82)$ \\
\hline Men & 96 & 3 & 1.00 \\
\hline \multicolumn{4}{|c|}{ Make me feel good } \\
\hline Women & 95 & 3 & $1.42(.71-2.84)$ \\
\hline Men & 91 & 6 & 1.00 \\
\hline \multicolumn{4}{|c|}{ Lose or manage weight } \\
\hline Women & 88 & 9 & $1.74(1.12-2.71)$ \\
\hline Men & 84 & 11 & 1.00 \\
\hline \multicolumn{4}{|c|}{ Help manage stress } \\
\hline Women & 85 & 8 & $1.52(.97-2.37)$ \\
\hline Men & 80 & 10 & 1.00 \\
\hline \multicolumn{4}{|c|}{ Improve appearance } \\
\hline Women & 81 & 13 & $2.93(2.07-4.15)$ \\
\hline Men & 60 & 24 & 1.00 \\
\hline \multicolumn{4}{|c|}{ Spend time with others } \\
\hline Women & 68 & 22 & $1.76(1.31-2.37)$ \\
\hline Men & 52 & 29 & 1.00 \\
\hline \multicolumn{4}{|c|}{ Meet new friends } \\
\hline Women & 58 & 27 & $1.76(1.31-2.36)$ \\
\hline Men & 38 & 36 & 1.00 \\
\hline
\end{tabular}

OR 95\%Cl: Odds Ratio 95\% Confidence Interval

Boldface indicates statistical significance $(p<.05)$

a Row percentages do not add up to $100 \%$, as percentages for 'Unsure' are not reported

${ }^{\mathrm{b}}$ Results from multilevel multinomial logistic regression: Odds ratio for 'agreement' versus 'disagreement' (not taking people who responded 'unsure' into account), adjusted for age, education, employment status, income, living arrangements, self-rated health, body mass index, psychological distress and physical activity level

The leading three PA context preferences, endorsed by more than two-thirds of the respondents, were 'activities close to home' ( $87 \%$ of women and $78 \%$ of men), at 'little or no cost' ( $80 \%$ of women, $73 \%$ of men) and activities that 'I can do on my own' ( $68 \%$ of women, $77 \%$ of men). For activity format, women were more likely than men to prefer activities at a fixed time (OR 1.42, 95\% CI $1.06-1.91)$ and less likely to prefer activities that are competitive (OR 0.32 , 95\%CI $0.22-0.46$ ), vigorous (OR 0.33 , 95\%CI $0.24-0.47$ ), skilled (OR 0.40 , 95\%CI 0.29 0.55 ), or done outdoors (OR $0.51,95 \%$ CI $0.30-0.86$ ). In terms of social setting, women were more likely to prefer activities with people of the same sex (OR 4.67, 95\% CI 3.14-6.94), supervised activities (OR 2.79, 95\%CI 1.944.02 ), and activities with people of the same age (OR $2.00,95 \%$ CI $1.43-2.78)$. Women tended to be less likely than men to prefer activities that could be done alone (OR 0.64, 95\%CI 0.40-1.00). 
Table 3 Agreement with context preferences stratified by gender and gender differences in the likelihood to agree

\begin{tabular}{|c|c|c|c|}
\hline & Agree $(\%)^{a}$ & Disagree $(\%)^{a}$ & $\begin{array}{l}\text { OR } 95 \% \mathrm{Cl} \text { for wome } \\
\text { compared to men }{ }^{b}\end{array}$ \\
\hline \multicolumn{4}{|l|}{ Format } \\
\hline \multicolumn{4}{|c|}{ Little or no cost } \\
\hline Women & 80 & 8 & $1.30(.81-2.08)$ \\
\hline Men & 73 & 9 & 1.00 \\
\hline \multicolumn{4}{|c|}{ Are not just about exercise } \\
\hline Women & 63 & 14 & $1.13(.77-1.68)$ \\
\hline Men & 55 & 15 & 1.00 \\
\hline \multicolumn{4}{|c|}{ Have a set routine or format } \\
\hline Women & 52 & 23 & $.79(.56-1.10)$ \\
\hline Men & 50 & 19 & 1.00 \\
\hline \multicolumn{4}{|c|}{ Done at a fixed time } \\
\hline Women & 44 & 35 & $1.42(1.06-1.91)$ \\
\hline Men & 32 & 41 & 1.00 \\
\hline \multicolumn{4}{|c|}{ Require skill and practice } \\
\hline Women & 23 & 47 & $.40(.29-.55)$ \\
\hline Men & 34 & 1 & 1.00 \\
\hline \multicolumn{4}{|c|}{ Are vigorous } \\
\hline Women & 24 & 51 & $.33(.24-.47)$ \\
\hline Men & 36 & 30 & 1.00 \\
\hline \multicolumn{4}{|c|}{ Involve competition } \\
\hline Women & 12 & 73 & $.32(.22-.46)$ \\
\hline Men & 22 & 52 & 1.00 \\
\hline \multicolumn{4}{|l|}{ Location } \\
\hline \multicolumn{4}{|c|}{ Close to home } \\
\hline Women & 87 & 4 & $1.45(.78-2.68)$ \\
\hline Men & 78 & 5 & 1.00 \\
\hline \multicolumn{4}{|c|}{ Done outdoors } \\
\hline Women & 62 & 10 & $.51(.30-.86)$ \\
\hline Men & 72 & 5 & 1.00 \\
\hline \multicolumn{4}{|l|}{ Social setting } \\
\hline \multicolumn{4}{|c|}{ Can do on my own } \\
\hline Women & 68 & 12 & $.64(.41-1.00)$ \\
\hline Men & 77 & 8 & 1.00 \\
\hline \multicolumn{4}{|c|}{ Done with people my age } \\
\hline Women & 58 & 18 & $2.00(1.43-2.78)$ \\
\hline Men & 42 & 25 & 1.00 \\
\hline \multicolumn{4}{|c|}{ Done with people my own sex } \\
\hline Women & 33 & 31 & $4.67(3.14-6.94)$ \\
\hline Men & 11 & 43 & 1.00 \\
\hline \multicolumn{4}{|c|}{ Involve supervision } \\
\hline Women & 26 & 48 & $2.79(1.94-4.02)$ \\
\hline Men & 12 & 63 & 1.00 \\
\hline
\end{tabular}

Table 3 Agreement with context preferences stratified by gender and gender differences in the likelihood to agree (Continued)

Are team-based
Women
Men

\section{Discussion}

Regular physical activity (PA) has health benefits across the life span, and among older adults there are specific benefits for physical, psychological and cognitive wellbeing. However, the proportion of people being sufficiently active for health benefits decreases with age. To promote PA in an ageing population, it is critical to have knowledge about what motivates older people to be active and what their preferences are, so as to optimize potential appeal and engagement. This study identified motivating factors and context preferences for PA in community dwelling adults aged 60-67 years and examined gender differences.

\section{Motivating factors}

People in this age group were more likely to be motivated by factors related to health and wellbeing, than by social factors. Almost all men and women endorsed preventing health problems and feeling good as motivating factors to do physical activity. This is in line with the findings of several systematic reviews summarizing PA motivators in people aged 50+ years [41], 65+ years [42], and $80+$ years [43].

Healthier people are more likely to participate in and adhere to exercise programs for preventative benefits [42]. However, half of the people aged $65+$ years have multiple long term health conditions or disabilities [44]. It may therefore be important to not only promote the preventative benefits of PA, but to also promote the potential benefits of regular PA for those with established health conditions, as research has demonstrated that PA can improve health related quality of life in older adults with physical [45, 46] and psychological conditions $[47,48]$. This is especially important as health problems are a key barrier to engage in PA for people aged 65+ years [42] and those aged $80+$ years [43]. The potential of a vicious cycle, in which people become less active because of their health problems, which in turn could result in further deterioration of their health, should be avoided. This could be done 
by ensuring that PA options and programs can be adapted to cater for the abilities of people with health problems [49]. The provision of these programs becomes more relevant as people age and the prevalence of chronic conditions and health problems affecting mobility and motivation increases. Although this may not be needed yet for people in their sixties, it is certainly relevant to think about potential adaptations to programs to ensure people in their seventies and eighties and ideally nineties and further can continue participation in PA programs. In addition, tailored programs could be developed for people with specific conditions, as has for example been done for cancer and arthritis $[50,51]$, to cater for the specific issues these people may face and provide a supportive environment for PA.

The motivating factor to "feel good" could also be used to promote PA opportunities for young older adults, including those with established health conditions. This may relate to enhancing positive wellbeing and selfimage; as well as managing psychological difficulties. There is a positive association between PA and positive perceptions of ageing in people aged 65-85 years [52], between PA and happiness in people in their seventies [53], and between PA and subjective wellbeing in people aged 60-64 years, even after accounting for long term illness [54]. Even low levels of PA can reduce the risk of future depression and anxiety in women in their seventies [55], and among those 50+ years [56] and those in their fifties and sixties [47] with depression, PA can improve mood, and physical and psychological healthrelated quality of life.

Social factors, such as spending time with others and meeting new friends, were endorsed by lower proportions of young older men and women than health related factors. This seems to contradict previous research identifying social support as a key motivator for PA in people aged 50+ years [41] and in those aged 80+ years [43]. It may be, however, that health and wellbeing benefits are valued more highly by young older adults when considering PA adoption, and that social factors are important for maintaining PA participation. Other research has identified a positive association between social support and adherence to programs and maintenance of physical activity $[49,57]$. Social support is a key determinant of healthy ageing [58], and PA programs may provide an excellent opportunity to create social networks to provide peer-support [49].

There were marked gender differences among young older adults in motivating factors related to appearance, weight and social factors. Women were two to three times more likely than men to be motivated by losing or managing weight and improving appearance. This is in line with findings for young girls and women [41]. The association between weight and health is complex in women as they age $[59,60]$. Intentional weight loss may benefit health and decrease the risk of chronic conditions in overweight and obese women in their fifties and seventies [60], however, there is also evidence that weight loss in adults in their late forties to mid-seventies can be a risk factor for age related conditions such as osteoporotic fractures [61]. Our finding that women in their sixties were almost twice as likely as men in their sixties to be motivated by social factors confirms previous findings in women aged 50+ years [19] and gender differences in social influence for exercise adoption [62].

\section{Context preferences}

Context preferences for PA have been less frequently examined than motivating factors. This study showed that more than three out of four young older adults preferred activities at little or no cost, close to home, and that they could do alone (men only). The preference for low cost activities reflects previous research where costs were reported as a main barrier to PA by people aged $50+$ years [41] and those aged 80+ years [43]. The preference for activities close to home is in line with previous findings that programs at inconvenient locations are associated with decreased participation by adults aged $50+$ years [19], and that adults aged 45+ years are less inclined to travel longer distances to PA opportunities than younger adults [63]. From a public health perspective, it is important therefore, that all young older people have access to PA options and programs, and low cost activities that can be done in their local area. Proximal destinations, and destinations that also facilitate some social interaction, have been identified as a key predictor of walking in adults aged $65+$ years $[64,65]$ and highlight the importance of a neighbourhood environment that is conducive to walking. Other environmental factors that are associated with more PA in this age group include safety, pedestrian infrastructure and connectivity, access to retail and services and aesthetics [66, 67]. Our Findings that adults in their sixties preferred activities that could be done alone is consistent with other research that a large proportion of people aged 50+ [19] and 60+ years [22] have a preference against structured classes. This may reflect concerns with keeping pace with younger people of higher ability, or being held back by older people of less ability.

There were marked gender differences among the young older adults in preferences for PA format, location and social setting. Women preferred activities at a fixed time, whereas men were more likely to prefer activities that require skill and practice, that are vigorous and that involve competition. In terms of location, men were more likely to prefer outdoor activities. In terms of social setting, women were more likely to prefer activities 
with people the same age, supervised activities and activities with other women. Thus, women have stronger preferences than men for who they are active with, which matches with the findings that they are more likely to be motivated by social factors [19]. Men had stronger preferences for the style of PA; their preference for skilled, vigorous, competitive and outdoor PA is characteristic of sports. Sports based PA options could therefore be appealing for young older men. There is a perception among men however, that the majority of community based sporting opportunities are primarily for young people [68]. As sport participation is associated with psychological and social health benefits [69] and because of the clear role of sports based PA for public health [70], the option to promote PA participation in young older men through sports based PA options should be further explored.

\section{Study strengths and limitations}

This study fills a gap in the literature by providing knowledge about PA motivators and context preferences in a population based sample of young old adults. This new evidence can inform the development of PA interventions for people in their sixties, who can have different interests from mid aged adults [30]. In contrast to many previous studies, these data were from a large population based sample, rather than from people participating in PA programs [19]. The results are therefore, more generalizable and less likely to reflect individual experiences with specific programs. Because of the large sample, it was possible to adjust the analyses for a range of sociodemographic and health related factors and PA. This study focused on adults in their sixties and so results may not be generalizable to adults older than this. In addition, respondents were from one major city in Australia, which may limit generalizability to those in other major cities or more regional areas. The style of assessment may have influenced results. For example, "preventing health problems" was provided as one possible motivator, but "managing current health problems" was not. It may be, therefore, that respondents who endorsed preventing health problems were motivated by potential health benefits but not prevention per se. Finally, contextual preferences may not always reflect the actual physical activity participation, which may be influenced by other factors such as available opportunities and logistics.

\section{Implications and conclusion}

PA opportunities for adults in their sixties should emphasize "preventing health problems" and "feeling good" as benefits as these were the main motivating factors for both men and women. Although women in this age group were also motivated by weight loss/management, caution may be needed given the potential health risks of low BMI among older adults. It may therefore be more useful to highlight benefits related to improved appearance and social opportunities, which were also important to women aged 60-67 years.

In terms of PA context preferences of adults in their sixties, it is important to prioritize PA options that are low cost, that can be done close to home and options outside of groups, as these were the key preferences. In addition, there were marked gender differences and there is a need to take these into account in the promotion and development of PA options for this age group. PA opportunities for women in their sixties may be more appealing if they are for women only, older adults only, supervised, and done at a fixed time. Men in their sixties may be more attracted to PA opportunities that have a degree of competition, are vigorous, skill-based, and outdoors.

Thus, although there is overlap in motivating factors and context preferences for PA in adults in their sixties, there are also marked gender differences. The results of this study suggest that PA options for people in their sixties should be tailored to meet gender specific interests in order to promote regular PA participation in this rapidly growing population group.

\section{Appendix 1}

List of items used to assess motivating factors.

There are different reasons why people might do physical activity. Which of these reasons could motivate you to do physical activity?

1. To prevent health problems

2. To help manage stress

3. To lose weight, or manage my weight

4. To spend time with others (e.g. friends, family, partner)

5. To improve my appearance

6. To make me feel good

7. To meet new friends

Response options: Strongly disagree; Disagree; Unsure; Agree; Strongly agree.

\section{Appendix 2}

List of items used to assess preferred activity context.

If you had the choice, what sort of physical activities would you prefer to do?

I would prefer to do activities that:

1. I can do on my own

2. Involve competition

3. Are done with people around my own age

4. Can be done close to home 
5. Are done outdoors

6. Require skill and practice

7. Have a set routine or format

8. Involve little or no cost

9. Involve supervision (e.g., from a leader)

10.Are team based

11.Are done at a fixed time (i.e., scheduled sessions)

12.Are done with people of my own sex

13.Are not just about exercise

14.Are vigorous

Response options: Strongly disagree; Disagree; No preferences; Agree; Strongly agree.

\section{Abbreviations}

95\% Cl: 95\% confidence interval; AUD: Australian dollar; BMl: Body mass index; CCD: Census collector's district; GLLAMM: Generalized linear latent and mixed models; MET: Metabolic equivalent; n: Number; OR: Odds ratio; PA: Physical activity; SD: Standard deviation

\section{Acknowlegdements}

We gratefully acknowledge HABITAT project staff for assistance with data coding and cleaning, and project management.

\section{Funding}

The HABITAT study was supported by project grants from the (Australian) National Health and Medical Research Council (NHMRC; ID497236), led by Professor Gavin Turrell, and at the time of data collection included Professor Brian Oldenburg, Professor Billie-Giles Corti, Dr. Nicola Burton, Dr. Michelle Haynes and Professor Wendy Brown, as chief investigators. At the time of data collection, NB was supported by a Heart Foundation Postdoctoral Fellowship (PH08B3905) and NB and JVU were supported by an NHMRC Program Grant (Owen, Bauman, Brown ID569940). At the time of writing, JvU was supported by an Australian Sports Commission - ISEAL Victoria University Senior Research Fellowship. The funding bodies did not contribute to the design of the study and collection, analysis, and interpretation of data and in writing the manuscript.

\section{Availability of data and materials}

The datasets used and/or analysed during the current study are available from NWB on reasonable request.

\section{Authors' contributions}

NB was involved in the coordination of data collection for the HABITAT study. JvU, NB and AK conceptualized the research questions and analyses presented in this paper and AK analyzed the data. All authors were involved in interpretation of the data. JVU wrote the first draft of the manuscript and NB and AK helped to further draft the manuscript. All authors read and approved the final manuscript

\section{Ethics approval and consent to participate}

Data were from the HABITAT study in Brisbane, Australia. The HABITAT study was approved by the Queensland University of Technology Human Research Ethics Committee $(3967 \mathrm{H})$. As this was a mail survey, there was no direct contact between researchers and participants. Survey return was therefore taken as informed consent. This form of consent was approved by the ethics committee.

\section{Consent for publication}

Not applicable.

\section{Competing interests}

The authors declare that they have no competing interests.

\section{Publisher's Note}

Springer Nature remains neutral with regard to jurisdictional claims in published maps and institutional affiliations.

\section{Author details}

Victoria University, Institute of Sport, Exercise and Active Living (ISEAL) (office PB140), PO Box 14428, Melbourne, VIC 8001, Australia. ${ }^{2}$ The University of Queensland, School of Human Movement and Nutrition Sciences, QLD, Brisbane 4072, Australia. ${ }^{3}$ Department of Kinesiology, Physical Activity, Sports and Health Research Group, KU Leuven - University of Leuven, B-3000 Leuven, Belgium. ${ }^{4}$ The University of Queensland, School of Health and Rehabilitation Sciences, QLD, Brisbane 4072, Australia.

Received: 9 January 2017 Accepted: 23 June 2017

Published online: 04 July 2017

\section{References}

1. National Institute on Aging, National Institutes of Health, U.S. Department of Health and Human Services, World Health Organization: Global Health and Aging: NIH Publication no. 11-7737; 2011.

2. Australian Bureau of Statistics: 3222.0 - Population Projections, Australia, 2012 (base) to 2101. Canberra; 2013. http://www.abs.gov.au/ausstats/abs@. nsf/mediareleasesbyCatalogue/7DB4DD841EA3A2A5CA2574 B9001E26F6?Opendocument. Accessed 8 July 2014.

3. United Nations, Department of Economic and Social Affairs, Population Division: World Population Ageing: ST/ESA/SER.A/348; 2013.

4. Agur K, McLean G, Hunt K, Guthrie B, Mercer SW. How does sex influence Multimorbidity? Secondary analysis of a large nationally representative dataset. Int J Environ Res Public Health. 2016;13(4):391.

5. Lee IM, Shiroma EJ, Lobelo F, Puska P, Blair SN, Katzmarzyk PT. Lancet physical activity series Working G: effect of physical inactivity on major noncommunicable diseases worldwide: an analysis of burden of disease and life expectancy. Lancet. 2012;380(9838):219-29.

6. Tak E, Kuiper R, Chorus A, Hopman-Rock M. Prevention of onset and progression of basic ADL disability by physical activity in community dwelling older adults: a meta-analysis. Ageing Res Rev. 2013;12(1):329-38.

7. Motl RW, McAuley E. Physical activity, disability, and quality of life in older adults. Phys Med Rehabil Clin N Am. 2010;21(2):299-308.

8. Bherer L, Erickson Kl, Liu-Ambrose T. A review of the effects of physical activity and exercise on cognitive and brain functions in older adults. Journal of aging research. 2013;2013:657508.

9. Mitchell T, Barlow CE. Review of the role of exercise in improving quality of life in healthy individuals and in those with chronic diseases. Current sports medicine reports. 2011;10(4):211-6.

10. World Health Organization. Global recommendations on physical activity for health. Geneva: World Health Organization; 2010.

11. Denkinger MD, Lukas A, Herbolsheimer F, Peter R, Nikolaus T. Physical activity and other health-related factors predict health care utilisation in older adults: the ActiFE Ulm study. Zeitschrift fur Gerontologie und Geriatrie. 2012;45(4):290-7.

12. Simmonds B, Fox K, Davis M, Ku PW, Gray S, Hillsdon M, Sharp D, Stathi A, Thompson J, Coulson J, et al. Objectively assessed physical activity and subsequent health service use of UK adults aged 70 and over: a four to five year follow up study. PLoS One. 2014;9(5):e97676.

13. Kohl HW 3rd, Craig CL, Lambert EV, Inoue S, Alkandari JR, Leetongin G, Kahlmeier S. Lancet physical activity series Working G: the pandemic of physical inactivity: global action for public health. Lancet. 2012;380(9838):294-305.

14. Begg S, Vos T, Barker B, Stevenson C, Stanley L, Lopez AD: The burden of disease and injury in Australia 2003. PHE 82. Canberra: Australian Institute of Health and Welfare; 2007.

15. Nelson ME, Rejeski WJ, Blair SN, Duncan PW, Judge JO, King AC, Macera CA, Castaneda-Sceppa C. Physical activity and public health in older adults: recommendation from the American College of Sports Medicine and the American Heart Association. Med Sci Sports Exerc. 2007:39(8):1435-45.

16. Sims J, Hill K, Hunt S, Haralambous B. Physical activity recommendations for older Australians. Australasian journal on ageing. 2010:29(2):81-7.

17. Hallal PC, Andersen LB, Bull FC, Guthold R, Haskell W, Ekelund U. Lancet physical activity series Working G: global physical activity levels: surveillance progress, pitfalls, and prospects. Lancet. 2012;380(9838):247-57.

18. Australian Bureau of Statistics: 4364.0.55.004 - Australian Health Survey: Physical Activity, 2011-12. Canberra; 2013. http://www.abs.gov.au/ausstats/ abs@.nsf/Lookup/D4495467B7F7EB01CA257BAC0015F593?opendocument. Accessed on 8th July 2014.

19. King AC: Interventions to promote physical activity by older adults. The journals of gerontology Series A, Biological sciences and medical sciences 2001, 56 Spec No 2:36-46. 
20. Wilcox S, King AC, Brassignton GS, Ahn DK. Physical activity preferences of middle-aged and older adults: a community analysis. J Aging Phys Act. 1999;7(4):386-99.

21. Booth ML, Bauman A, Owen N, Gore CJ. Physical activity preferences, preferred sources of assistance, and perceived barriers to increased activity among physically inactive Australians. Prev Med. 1997;26(1):131-7.

22. Salmon J, Owen N, Crawford D, Bauman A, Sallis JF. Physical activity and sedentary behavior: a population-based study of barriers, enjoyment, and preference. Health psychology : official journal of the Division of Health Psychology, American Psychological Association. 2003;22(2):178-88.

23. Beauchamp MR, Carron AV, McCutcheon S, Harper O. Older adults' preferences for exercising alone versus in groups: considering contextual congruence. Annals of behavioral medicine: a publication of the Society of Behavioral Medicine. 2007;33(2):200-6.

24. Hankonen N, Absetz P, Ghisletta P, Renner B, Uutela A. Gender differences in social cognitive determinants of exercise adoption. Psychol Health. 2010;25(1):55-69.

25. Phongsavan P, McLean G, Bauman A. Gender differences in influences of perceived environmental and psychosocial correlates on recommended level of physical activity among new Zealanders. Psychol Sport Exerc. 2007;8(6):939-50.

26. Sun F, Norman IJ, While AE. Physical activity in older people: a systematic review. BMC Public Health. 2013;13:449.

27. Koeneman MA, Verheijden MW, Chinapaw MJ, Hopman-Rock M Determinants of physical activity and exercise in healthy older adults: a systematic review. The international journal of behavioral nutrition and physical activity. 2011;8:142.

28. Burton NW, Haynes M, Wilson LA, Giles-Corti B, Oldenburg BF, Brown WJ, Giskes K, Turrell G. HABITAT: a longitudinal multilevel study of physical activity change in mid-aged adults. BMC Public Health. 2009;9:76.

29. Peeters G, Brown W, Burton N. Physical activity context preferences in people with arthritis and osteoporosis. J Phys Act Health. 2014;11(3):536-42.

30. Burton NW, Khan A, Brown WJ. How, where and with whom? Physical activity context preferences of three adult groups at risk of inactivity. $\mathrm{Br}$ J Sports Med. 2012;46(16):1125-31.

31. Khan A, Brown WJ, Burton NW. What physical activity contexts do adults with psychological distress prefer? Journal of science and medicine in sport / Sports Medicine Australia. 2013;16(5):417-21.

32. Bandura A. Social foundations of thought and action: a social cognitive theory. Prentice Hall: Englewood Cliffs, NJ; 1986.

33. Dzewaltowski DA. Physical activity determinants: a social cognitive approach. Med Sci Sports Exerc. 1994;26(11):1395-9.

34. World Health Organization. Obesity: preventing and managing the global epidemic. Geneva: World Health Organization; 2000.

35. Kessler RC, Andrews G, Colpe LJ, Hiripi E, Mroczek DK, Normand SL, Walters EE, Zaslavsky AM. Short screening scales to monitor population prevalences and trends in non-specific psychological distress. Psychol Med. 2002;32(6):959-76.

36. Kessler RC, Green JG, Gruber MJ, Sampson NA, Bromet E, Cuitan M, Furukawa TA, Gureje O, Hinkov H, Hu CY, et al. Screening for serious mental illness in the general population with the K6 screening scale: results from the WHO World mental health (WMH) survey initiative. Int J Methods Psychiatr Res. 2010;19(Suppl 1):4-22.

37. Australian Institute of Health and Welfare. The active Australia survey: a guide and manual for implementation, analysis and reporting. Canberra: Australian Institute of Health and Welfare; 2003.

38. Brown WJ, Burton NW, Marshall AL, Miller YD. Reliability and validity of a modified self-administered version of the active Australia physical activity survey in a sample of mid-age women. Aust N Z J Public Health. 2008;32(6):535-41.

39. Heesch KC, Hill RL, van Uffelen JG, Brown WJ. Are active Australia physical activity questions valid for older adults? Journal of science and medicine in sport / Sports Medicine Australia. 2011;14(3):233-7.

40. Rabe-Heskteh SSA, Pickles A. Reliable estimation of generalized linear mixed models using adaptive quadrature. Stata J. 2002;2:1-21.

41. Allender S, Cowburn G, Foster C. Understanding participation in sport and physical activity among children and adults: a review of qualitative studies. Health Educ Res. 2006;21(6):826-35.

42. Schutzer KA, Graves BS. Barriers and motivations to exercise in older adults. Prev Med. 2004;39(5):1056-61.

43. Baert V, Gorus E, Mets T, Geerts C, Bautmans I. Motivators and barriers for physical activity in the oldest old: a systematic review. Ageing Res Rev. 2011;10(4):464-74
44. Australian Institute of Health and Welfare: Australia's health 2014. Australia's health series no. 14. Cat. no. AUS 178. Canberra: Australian Institute of Health and Welfare; 2014.

45. Courneya KS, Tamburrini AL, Woolcott CG, McNeely ML, Karvinen KH, Campbell KL, McTiernan A, Friedenreich CM. The Alberta physical activity and breast cancer prevention trial: quality of life outcomes. Prev Med. 2011; 52(1):26-32.

46. Johnson BL, Trentham-Dietz A, Koltyn KF, Colbert LH. Physical activity and function in older, long-term colorectal cancer survivors. Cancer causes \& control: CCC. 2009;20(5):775-84.

47. Heesch KC, van Gellecum YR, Burton NW, van Uffelen JG, Brown WJ. Physical activity, walking, and quality of life in women with depressive symptoms. Am J Prev Med. 2015;48(3):281-91.

48. Heesch KC, van Gellecum YR, Burton NW, van Uffelen JGZ, Brown WJ. Physical activity and quality of life in older women with a history of depressive symptoms. Prev Med. 2016;91:299-305.

49. Task Force on Community Preventive $\mathrm{S}$. Recommendations to increase physical activity in communities. Am J Prev Med. 2002;22(4 Suppl):67-72.

50. Reynolds J, Thibodeaux L, Jiang L, Francis K, Hochhalter A. Fit \& strong! Promotes physical activity and well-being in older cancer survivors. Front Public Health. 2014:2:171.

51. Wilcox S, McClenaghan B, Sharpe PA, Baruth M, Hootman JM, Leith K, Dowda M. The steps to health randomized trial for arthritis: a self-directed exercise versus nutrition control program. Am J Prev Med. 2015;48(1):1-12.

52. Beyer AK, Wolff JK, Warner LM, Schuz B, Wurm S. The role of physical activity in the relationship between self-perceptions of ageing and selfrated health in older adults. Psychol Health. 2015;30(6):671-85.

53. Khazaee-Pool M, Sadeghi R, Majlessi F, Rahimi Foroushani A. Effects of physical exercise programme on happiness among older people. J Psychiatr Ment Health Nurs. 2015;22(1):47-57.

54. Black SV, Cooper R, Martin KR, Brage S, Kuh D, Stafford M. Physical activity and mental well-being in a cohort aged 60-64 years. Am J Prev Med. 2015; 49(2):172-80.

55. Heesch KC, Burton NW, Brown WJ. Concurrent and prospective associations between physical activity, walking and mental health in older women. $J$ Epidemiol Community Health. 2011:65(9):807-13.

56. Blake H, Mo P, Malik S, Thomas S. How effective are physical activity interventions for alleviating depressive symptoms in older people? A systematic review. Clin Rehabil. 2009;23(10):873-87.

57. McAuley E, Jerome GJ, Elavsky S, Marquez DX, Ramsey SN. Predicting longterm maintenance of physical activity in older adults. Prev Med. 2003;37(2): $110-8$.

58. World Health Organization. Active ageing: a policy framework. Geneva: World Health Organization; 2002. http://apps.who.int/iris/bitstream/10665/ 67215/1/WHO_NMH_NPH_02.8.pdf. Accessed 14 July 2015.

59. van Uffelen JG, Berecki-Gisolf J, Brown WJ, Dobson AJ. What is a healthy body mass index for women in their seventies? Results from the Australian longitudinal study on women's health. J Gerontol A Biol Sci Med Sci. 2010; 65(8):847-53.

60. van Uffelen JG, Brown WJ. BMI and longevity in women: a time for reflection? Maturitas. 2010;67(4):294-5.

61. Dai Z, Ang LW, Yuan JM, Koh WP. Association between change in body weight after midlife and risk of hip fracture-the Singapore Chinese health study. Osteoporosis international: a journal established as result of cooperation between the European Foundation for Osteoporosis and the National Osteoporosis Foundation of the USA. 2015;

62. Troped PJ, Saunders RP. Gender differences in social influence on physical activity at different stages of exercise adoption. American journal of health promotion: AJHP. 1998;13(2):112-5.

63. McCormack GR, Giles-Corti B, Bulsara M, Pikora TJ. Correlates of distances traveled to use recreational facilities for physical activity behaviors. The international journal of behavioral nutrition and physical activity. 2006;3:18.

64. Nathan A, Pereira G, Foster S, Hooper P, Saarloos D, Giles-Corti B. Access to commercial destinations within the neighbourhood and walking among Australian older adults. The international journal of behavioral nutrition and physical activity. 2012;9:133.

65. Nathan A, Wood L, Giles-Corti B. Exploring socioecological correlates of active living in retirement village residents. J Aging Phys Act. 2014:22(1):1-15.

66. Moran M, Van Cauwenberg J, Hercky-Linnewiel R, Cerin E, Deforche B, Plaut $P$. Understanding the relationships between the physical environment and physical activity in older adults: a systematic review of qualitative studies. 
The international journal of behavioral nutrition and physical activity 2014;11:79.

67. Yen IH, Fandel Flood J, Thompson H, Anderson LA, Wong G. How design of places promotes or inhibits mobility of older adults: realist synthesis of 20 years of research. Journal of aging and health. 2014;26(8):1340-72.

68. Burton NW, Walsh A, Brown WJ. It just doesn't speak to me: mid-aged men's reactions to '10,000 steps a Day'. Health promotion journal of Australia: official journal of Australian Association of Health Promotion Professionals. 2008;19(1):52-9.

69. Eime RM, Young JA, Harvey JT, Charity MJ, Payne WR. A systematic review of the psychological and social benefits of participation in sport for adults: informing development of a conceptual model of health through sport. The international journal of behavioral nutrition and physical activity. 2013;10:135

70. Khan KM, Thompson AM, Blair SN, Sallis JF, Powell KE, Bull FC, Bauman AE. Sport and exercise as contributors to the health of nations. Lancet. 2012; 380(9836):59-64.

Submit your next manuscript to BioMed Central and we will help you at every step:

- We accept pre-submission inquiries

- Our selector tool helps you to find the most relevant journal

- We provide round the clock customer support

- Convenient online submission

- Thorough peer review

- Inclusion in PubMed and all major indexing services

- Maximum visibility for your research

Submit your manuscript at www.biomedcentral.com/submit 